\title{
Morphological Variability \\ of Leonurus quinquelobatus (Lamiaceae): Environmental and Resource Potential Perspective
}

\author{
Yulia V. Zagurskaya**, \\ Tatyana I. Siromlya ${ }^{\mathrm{b}}$ and Irina I. Bayandina ${ }^{\mathrm{c}}$ \\ ${ }^{a}$ Federal Research Center on Coal and Coal Chemistry SB RAS \\ «Institute of Human Ecology» \\ Kemerovo, Russian Federation \\ ${ }^{b}$ Institute of Soil Science and Agrochemistry SB RAS \\ Novosibirsk, Russian Federation \\ ${ }^{c}$ Novosibirsk State Agrarian University \\ Novosibirsk, Russian Federation
}

Received 10.03.2020, received in revised form 24.07.2020, accepted 19.11.2020

\begin{abstract}
The influence of the environment on the studied characteristics can be determined when growing genetically similar plants in different environmental conditions. The medicinal plant Leonurus quinquelobatus Gilib. (five-bladed motherwort) belongs to a group of plants that are most responsive to changes of environmental conditions. Plants were grown from genetically uniform seeds in trial plots in three different southern regions of West Siberia (Kemerovo, Novosibirsk, and Kamlak Village, Altai Republic). Measurements were performed for 10 model live plants in each trial plot three times per growing season during three years. Variability of 23 vegetative and generative traits was studied based on linear, quantitative, and calculated data. The following traits correlated significantly with the phase of development: height of plant; branching of first-order shoots; length of the generative parts; inflorescence size share in plant height; width of generative part of the shoot; number of generative internodes of the first-order shoot; numbers of internodes with buds, flowers, and fruit; flowering index; fruiting index. The following traits changed significantly in different habitats: plant height; branching of first-order shoots; all generative traits studied. The branching and flowering indices changed due to the interaction of factors. The projection area of the aboveground part and the number of third-order shoots on a second-order shoot did not depend significantly on either the development phase or the growing region. For further research, the number of morphological traits under study could be reduced depending on the aims of the research.
\end{abstract}

(C) Siberian Federal University. All rights reserved

This work is licensed under a Creative Commons Attribution-NonCommercial 4.0 International License (CC BY-NC 4.0).

* Corresponding author E-mail address: syjil@mail.ru ORCID: 0000-0001-8101-0945 (Zagurskaya Yu.); 0000-0002-0155-2283 (Siromlya T.); 0000-0002-4380-6800 (Bayandina I.) 
Keywords: five-bladed motherwort, morphology, phase of development, different habitats ecology, raw materials.

Acknowledgments: The authors would like to thank their colleagues from Novosibirsk SAU (Novosibirsk), Kuzbass Botanical Garden of Institute of Human Ecology FRC CCC SB RAS (Kemerovo) and GornoAltaysk Botanical Garden (village Kamlak) for their participation and growing and collecting plants used in the research. The authors are also grateful to their anonymous peer reviewers for their invaluable comments and suggestions which helped us to improve the original text. This research was carried out as part of the Kuzbass Botanical Garden Department FRC CCC SB RAS, ISSA SB RAS and NSAU State Assignment projects.

Citation: Zagurskaya Yu.V., Siromlya T. I., Bayandina I. I. Morphological variability of Leonurus quinquelobatus (Lamiaceae): environmental and resource potential perspective. J. Sib. Fed. Univ. Biol., 2021, 14(1), 28-42. DOI: 10.17516/1997-1389-0339

\title{
Морфологическая изменчивость
}

\section{Leonurus quinquelobatus (Lamiaceae):}

\section{Экологическая и сырьевая значимость}

\author{
Ю.В. Загурская ${ }^{a}$, Т.И. Сиромляб ${ }^{6}$ И. И. Баяндина \\ ${ }^{a}$ Федеральный исследовательский центр угля \\ и углехимии СО РАН \\ (Институт экологии человека) \\ Российская Федерация, Кемерово \\ ${ }^{6}$ Институт почвоведения и агрохимии СО РАН \\ Российская Федерация, Новосибирск \\ ${ }^{8}$ Новосибирский государственный аграрный университет \\ Российская Федерация, Новосибирск
}

\begin{abstract}
Аннотация. Влияние окружающей среды на исследуемые признаки можно выявить при выращивании генетически сходных растений в различающихся экологических условиях. Leonurus quinquelobatus Gilib. (пустырник пятилопастный) - лекарственное растение - чувствителен к изменению экологических условий. Растения выращивали из генетически однородных семян на опытных участках г. Кемерова, г. Новосибирска, с. Камлак Республики Алтай. Измерения проводили на каждой опытной площадке по три раза за вегетационный период в течение трех лет на 10 модельных живых растениях. Изучена изменчивость 23 линейных, количественных и расчетных признаков вегетативной и генеративной сферы. Следующие признаки статистически значимо изменяются в зависимости от фазы развития: высота растения; ветвление побегов первого порядка; длина генеративной части; доля соцветия в высоте растения; ширина генеративной части побега; число цветущих междоузлий осевой части первого побега; число междоузлий с бутонами, с цветками, с плодами; индекс цветения; индекс плодоношения. В разных местах произрастания
\end{abstract}


статистически значимо различаются следующие признаки: высота растения; ветвление побегов первого порядка; все изученные нами признаки генеративной сферы. Индекс ветвления и индекс цветения изменяются из-за взаимовлияния факторов. Площадь проекции надземной части и число побегов третьего порядка на побеге второго порядка статистически значимо не зависят ни от фазы развития, ни от региона произрастания. В дальнейших исследованиях число изучаемых морфологических признаков можно ограничивать в зависимости от цели исследования.

Ключевые слова: пустырник пятилопастный, морфологические признаки, фазы развития, регион произрастания, экология, ресурсы.

Благодарности: Авторы выражают признательность сотрудникам Новосибирского ГАУ (г. Новосибирск), Кузбасского ботанического сада Института экологии человека ФИЦ УУХ СО РАН (г. Кемерово) и Горно-Алтайского ботанического сада (с. Камлак) за участие в выращивании и сборе материала для исследования. Авторы выражают благодарность анонимным рецензентам, чьи замечания и рекомендации способствовали значительному улучшению текста статьи. Работа выполнена в рамках проектов гос. заданий отдела Кузбасский ботанический сад ФИЦ УУХ СО РАН, ИПА СО РАН и НГАУ.

Цитирование: Загурская, Ю.В. Морфологическая изменчивость Leonurus quinquelobatus (Lamiaceae): экологическая и сырьевая значимость / Ю.В. Загурская, Т.И. Сиромля, И.И. Баяндина // Журн. Сиб. федер. ун-та. Биология, 2021. 14(1). C. 28-42. DOI: $10.17516 / 1997-1389-0339$

\section{Введение}

В настоящее время интерес к исследованию морфологических признаков видов рода Leonurus L. связан не только с установлением таксоноспецифических особенностей (Marciniuk et al., 2014; Pitschmann et al., 2017), но и с поиском отличительных признаков для растений, произрастающих в различных условиях (Ganeva et al., 2015; Комаревцева, Курочкина, 2018; Макрушин и др., 2017).

Возрастное состояние растений зависит и от календарного возраста организма, и от условий выращивания, и от региона обитания. Нами ранее было показано, что размеры растений Leonurus quinquelobatus Gilib. (пустырника пятилопастного) одного возраста и выращенных из генетически однородного материала в разных регионах Западной Сибири могут существенно различаться (Загурская и др., 2013). Ученые ЦБС НАН Беларуси отмечали, что с наступлением цветения заметно слабели функции линейного роста побегов, однако возрастало формирование ассимиляционных органов (Рупасава и др., 1994); также установлено значительное влияние удобрений и стимуляторов роста на урожайность лекарственного растительного сырья этой культуры при многолетнем возделывании (Тарасенко и др., 2008; Ермохин и др., 2012).

L. quinquelobatus - рудеральное многолетнее травянистое прямостоячее корневищное растение, опушенное длинными мягкими волосками. В природе цветет с июня до сентября, плоды созревают в августе-октябре. Европейско-кавказский вид, заходящий восточным краем ареала в Западную Сибирь (Губанов и др., 2004).

Трава пустырника (Herba Leonuri) - верхние части стеблей L. quinquelobatus (пустырник пятилопастный) и Leonurus cardiaca L. (пустырник сердечный) с цветками и листья- 
ми - применяется в официальной медицине России в качестве седативного средства (Государственная Фармакопея РФ..., 2018), кроме того, известны нейро- и кардиопротекторные свойства растений рода (Ritter et al., 2010; Rastogi et al., 2016). Морфологические изменения зачастую влияют на объем и качество получаемого сырья лекарственных растений. Выявление перспектив выращивания пустырника представляет практический интерес, поскольку заготовка сырья пустырника в Западной Сибири в настоящее время идет только в естественных условиях произрастания и сопряжена с рядом трудностей (Ермохин и др., 2012).

На изучении морфометрических параметров в разных экологических условиях также основано выявление способности растений к адаптации. L. quinquelobatus в природе обладает высокой экологической пластичностью и низкой конкурентной мощностью: способен очень быстро захватывать свободные экотопы и так же легко вытесняется конкурентами. Соответственно, развитие экземпляров пустырника в различных условиях, в том числе дикорастущих и культивируемых, различается значительно. Таким образом, изучение особенностей развития L. quinquelobatus в условиях культуры также актуально с точки зрения аутэкологии.

Цель работы: выявить различия морфологических параметров и особенности роста и развития растений L. quinquelobatus в различных агропопуляциях на территории Западной Сибири.

\section{Материалы и методы}

Растения L. quinquelobatus выращивали в 2010-2012 гг. из генетически однородных семян, собранных в условиях культуры в г. Кемерово в 2009 г., на опытных участках: Кузбасского ботанического сада (Институт экологии человека ФИЦ УУХ СО РАН, г. Кемерово); Сада Мичуринцев НГАУ (ФГБОУ ВПО «Новосибирский государственный аграрный университет», г. Новосибирск); Горно-Алтайского ботанического сада (АЛТФ ЦСБС СО РАН «Горно-Алтайский ботанический сад», с. Камлак Республики Алтай). Площадки были расположены на открытых местах (без затеняющих объектов поблизости). Расстояние между растениями в рядах составляло 50 см, между рядами $-70 \mathrm{~cm}$.

Регионы проведения исследований находятся на юге Западной Сибири и имеют сходные среднегодовые показатели и тенденции изменения климатических факторов (Загурская и др., 2012; Загурская, Сиромля, 2018). Почвы экспериментальных участков различаются и подробно охарактеризованы в работе (Сиромля и др., 2017).

Измерения проводили в 2012 г. (3-й год жизни) на каждой опытной площадке по три раза за сезон с интервалами в $21 \pm 2$ дня на 10 пронумерованных модельных живых растениях из средней части площадок, по результатам первичной визуальной оценки обладавших средними размерами. Начало отсчета времени измерений соответствовало началу цветения, т. е. даты снятия измерений в каждом регионе различались.

В Новосибирске (НСК): измерение 1 произведено 22.06, измерение 2-12.07, измерение 3-01.08; в Кемерово (КЕ): измерение 1-27.06, измерение 2-19.07, измерение 3-10.08; в с. Камлак (Респ. Алтай) (РА): измерение 1-04.07, измерение 2-25.07, измерение 3-15.08.

Условно эти этапы можно обозначить как «начало цветения» - распускание первых (нижних) цветков меньше чем на 1/2 мутовок, «середина цветения» - раскрылись цветки на большей части мутовок, в верхней части соцветия могут присутствовать бутоны, в нижней - начинают формироваться семена, 
«конец цветения» - начало созревания семян, цветение только в верхней части соцветий, бутонов нет.

Для оценки использовали линейные, количественные и расчетные параметры.

1. Характеризующие вегетативную сфеpy:

- высота растения (Н), см;

- площадь проекции надземной части (S), $\mathrm{M}^{2}$;

- суммарное число побегов первого порядка $\left(\mathrm{N}_{1}\right)$, шт.;

- число побегов первого порядка с генеративными органами $\left(\mathrm{N}_{\mathrm{g} 1}\right)$, шт.;

- число побегов второго порядка на одном побеге $\left(\mathrm{N}_{2}\right)$, шт.;

- число побегов третьего порядка на побег второго порядка $\left(\mathrm{N}_{3}\right)$, шт.;

- ветвление побегов первого порядка $\left(\mathrm{N}_{1} \times \mathrm{N}_{2}\right)$;

- индекс ветвления $\left(\mathrm{N}_{2} / \mathrm{N}_{1}\right)$.

2. Характеризующие генеративную сфеpy:

- длина генеративной части $\left(\mathrm{H}_{\mathrm{g}}\right), \mathrm{cm}$;

- доля соцветия в высоте растения $\left(\mathrm{H}_{\mathrm{g}} / \mathrm{H}\right), \%$;

- ширина генеративной части побега $\left(\mathrm{B}_{\mathrm{g}}\right), \mathrm{cm}$;

- число мутовок на осевой части первого побега $\left(\mathrm{N}_{\mathrm{Mt}}\right)$, шт.;

- число мутовок с бутонами $\left(\mathrm{N}_{\mathrm{MtB}}\right)$, шт.;

- число мутовок с цветками $\left(\mathrm{N}_{\mathrm{MtF}}\right)$, шт.;

- число мутовок с плодами $\left(\mathrm{N}_{\mathrm{MtP}}\right)$, шт.;

- индекс цветения (ИЦ= $\left.\mathrm{N}_{\mathrm{MtF}} / \mathrm{N}_{\mathrm{Mt}}\right), \%$;

- индекс плодоношения (ИП= $\left.\mathrm{N}_{\mathrm{MtP}} / \mathrm{N}_{\mathrm{Mt}}\right)$, $\%$.

3. Параметры листьев:

- число узлов стеблевых листьев, шт.;

- узел расположения нижнего листа;

- длина черешка, см;

- длина листа, см;

- ширина листа, см;
- степень повреждения, \%.

В связи с отличием распределения данных от нормального и неоднородностью дисперсий во многих выборках был проведен однофакторный непараметрический анализ по методу Краскела-Уоллиса для фактора «место произрастания» и однофакторный непараметрический анализ по методу Фридмана для фактора «фаза развития». Апостериорные сравнения были выполнены по методам Манна-Уитни и Уилкоксона соответственно. Для анализа взаимодействия факторов дополнительно был проведен двухфакторный непараметрический анализ по Уилсону, однако в данном случае его нельзя считать полностью корректным, поскольку фактор «фаза развития» является зависимым. Во всех процедурах статистического анализа критический уровень значимости р принимался равным 0,05 .

\section{Результаты и обсуждение}

Результаты изучения морфологических признаков растений L. quinquelobatus 3-го года жизни, культивируемых в условиях юга Западной Сибири, представлены в табл. 1-3 и на рисунке.

Рост растения как физиологический процесс обладает высокой чувствительностью и лабильностью к изменению напряженности внутренних и внешних факторов (Шевелуха, 1971).

Высота растений второго года жизни в разных регионах Западной Сибири различалась менее существенно по сравнению с первым годом эксперимента, когда разница между средними значениями составила около 50 \% (Новосибирск - 30,5 см, Кемерово 14,6 см, Камлак - 6,1 см). В конце вегетационного сезона 2011 г. высота новосибирских растений превышала кемеровские и алтайские показатели на 15 и 20 \% соответствен- 


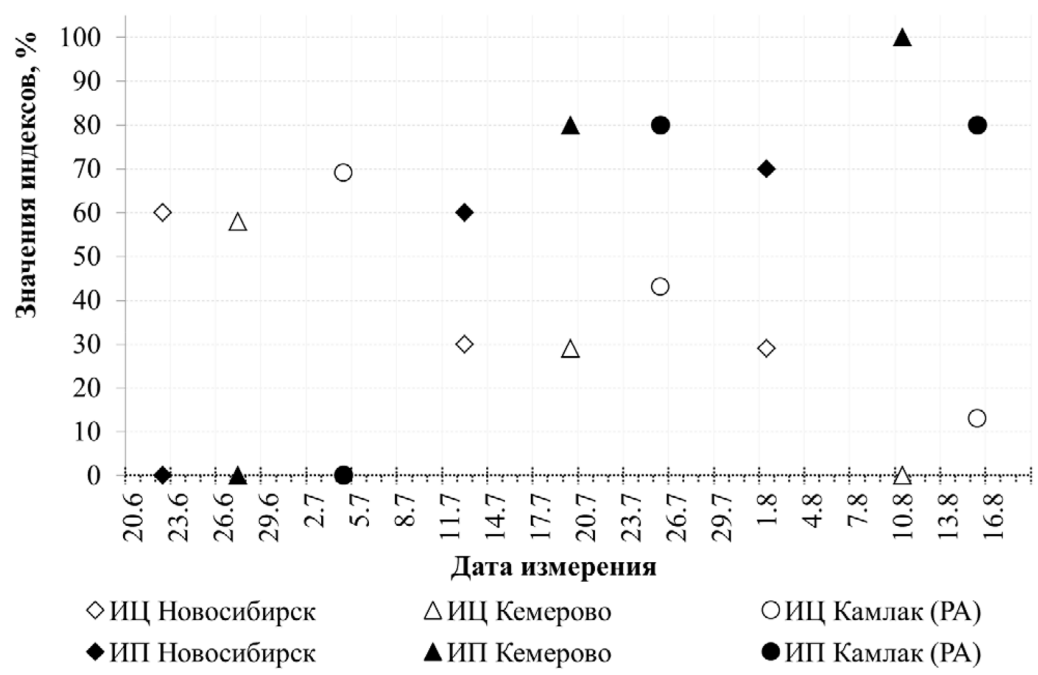

Рис. 1. Сезонная динамика генеративных процессов (индекс цветения - ИЦ и индекс плодоношения ИП) у растений L. quinquelobatus в трех регионах Западной Сибири

Fig. 1. Seasonal dynamics of generative processes in L. quinquelobatus (flowering index - ИЦ and fruiting index - ИП) in three regions of West Siberia

но, однако тенденция уменьшения размеров в ряду Новосибирск-Кемерово-Камлак сохранялась (Загурская, Баяндина, 2015a). Активность ростовых процессов после начала цветения характеризует обратная зависимость: минимальное увеличение высоты растений за июль-август 2011 и 2012 гг. для растений в генеративной фазе зафиксировано в Новосибирске, максимальное - на Алтае, в Кемерове отмечены промежуточные значения показателей.

Высота растений третьего года жизни в разных регионах изменялась еще меньше (табл. 1), что подтверждает заключение белорусских ученых о наибольшей интенсивности биопродукционных процессов в период первого и второго годов вегетации (Рупасава и др., 1994). В 2012 г. у растений третьего года жизни максимальная высота надземной части характеризовала алтайские экземпляры, растения из Новосибирска и Кемерова между собой существенно не различались.

Минимальная разница между растениями за период измерений отмечена в Но- восибирске, т. е. новосибирские растения прекратили активный рост еще до 22 июня. В Кемерове между первым и третьим измерениями наблюдались достоверные различия, но значения были близки к пограничным. Наиболее значительная динамика роста растений за период наблюдений характерна для Камлака, причем пик роста замечен между первым и вторым измерениями. Между экземплярами из Кемерова и Новосибирска в сходные фазы вегетации достоверных различий по высоте не обнаружено. Статистически значимая разница отмечена для растений в Камлаке по сравнению с другими регионами.

По данным ряда авторов, высота растений в период цветения достигает 130-160 см, но для дикорастущих экземпляров пустырника значительной считают высоту 60-70 см и длину соцветий около 20 см (Bozek, 2000; Чудновская, 2013; Макрушин и др., 2017), т. е. размер растений L. quinquelobatus, культивируемых в условиях юга Западной Сибири, сравним с выращиваемыми в Нечерноземной 
зоне и существенно превышает природные растения.

Ветвление растений - способ увеличения площади ассимиляционной поверхности и биомассы растений. Для разветвленности растений пустырника отмечены характерные региональные различия. В начале цветения статистически значимые отличия отмечаются только для алтайских растений, но затем для всех вариантов различия существенны. Наибольшую разветвленность отмечали для новосибирских растений, наименьшую - для алтайских (табл. 1).

Индекс ветвления при проверке 2-факторным непараметрическим дисперсионным анализом данных по Уилсону ни региональных, ни сезонных различий не показал, но отмечается статистически значимая разница сезонной динамики развития данного признака (взаимовлияние факторов).

Одной из характеристик, отражающих размеры растений, считается площадь проекции надземной части, но при сравнении растений L. quinquelobatus в условиях Западной Сибири различия этого показателя оказались статистически не значимы и не зависимы не только от места произрастания, но и стадии цветения.

Центральным моментом развития растительного организма является переход от вегетативного роста к репродуктивному развитию, при этом условия среды могут влиять на реализацию генетической информации и тем самым ускорять или замедлять наступление определенных этапов развития, в первую очередь переход растения от этапа молодости к этапу зрелости. Мелкие розовые цветки пустырника собраны густыми мутовками в пазухах верхних листьев, образуя длинное прерванное колосовидное соцветие на концах стеблей и ветвей. В пазухах прицветных листьев находятся парциальные со- цветия, образующие ложные мутовки, представляющие собой дихазии (Гаммерман и др., 1983; Тарасенко и др., 2008).

Кроме того, показатели, характеризующие генеративную сферу растений, отражают один из наиболее важных аспектов приспособления растений к условиям окружающей среды - способность к семенному размножению и его особенности. Известно, что замедление темпов развития и повышение выживаемости за счет снижения репродуктивной функции являются приспособлениями организма, которые дают возможность избегать критического состояния (Заугольнова и др., 1992). Для пустырника пятилопастного характерно мутовчатое тирозоидное соцветие (Романюк, 2012) или длинное прерывистое колосовидное соцветие (Губанов и др., 2004), место начала соцветия отмечают продолговато-ромбические, двунадрезанные или двузубчатые листья с короткими черешками. На культивируемых растениях наблюдается разветвление генеративных побегов в точке начала соцветия с образованием трех векторов роста, развитых более-менее одинаково. Дикорастущие экземпляры, как правило, обладают короткими соцветиями с недоразвитыми боковыми осями.

Для всех изученных параметров генеративной сферы отмечены существенные различия вариантов.

Количество генеративных побегов первого порядка у изученных растений почти полностью совпадало с общим числом побегов, что говорит о завершении активной вегетации к фазе начала цветения, и за период измерений практически не изменилось, демонстрируя существенно большее разветвление растений из Новосибирска и Кемерова по сравнению с алтайскими экземплярами (Загурская, Баяндина, 2015b). 


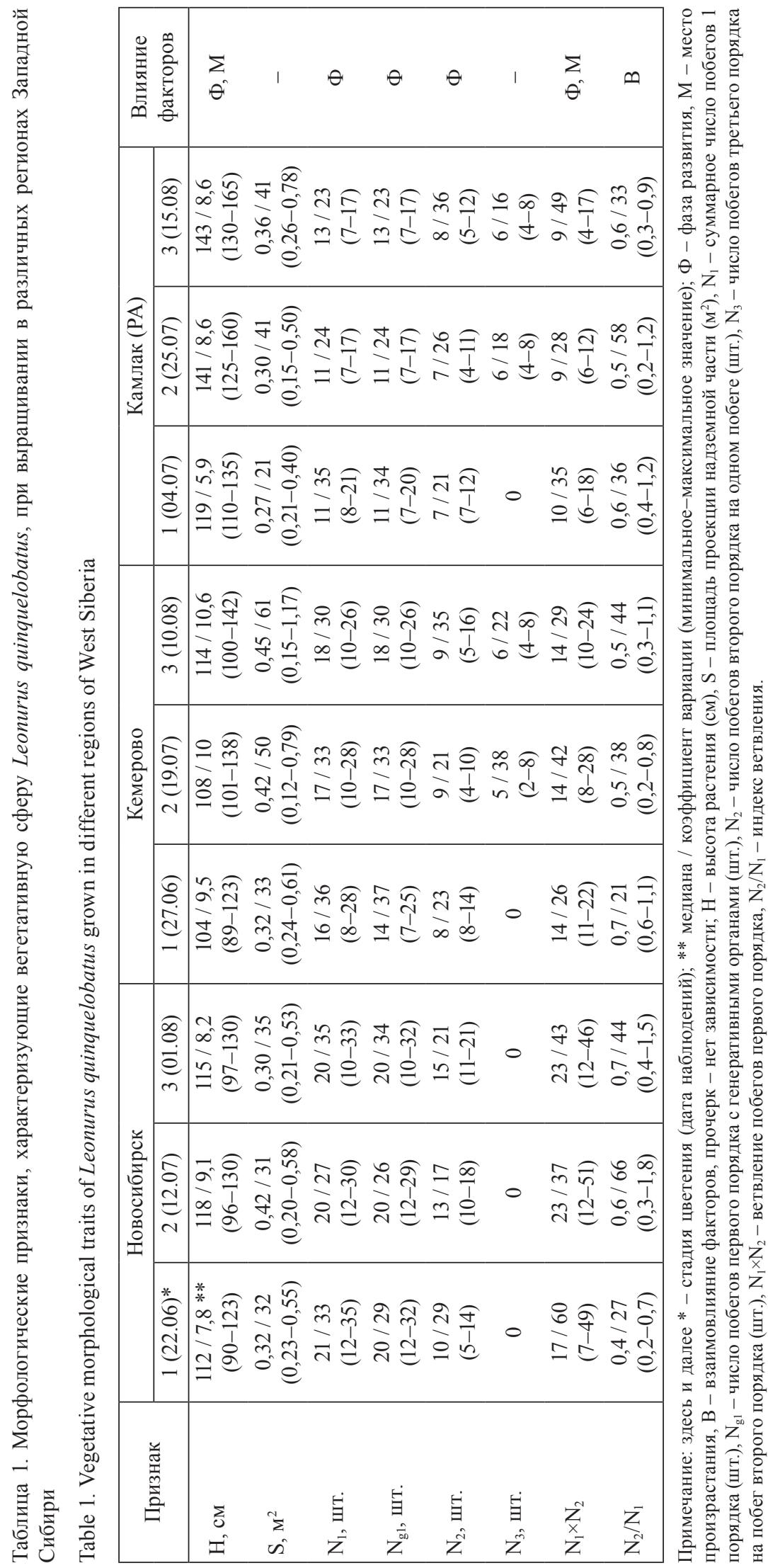


Длина центральной части соцветия $(\mathrm{Hg}$, см) у растений пустырника, культивируемых в условиях Западной Сибири, во все периоды измерений была максимальной на Алтае, несколько меньше в Новосибирске и Кемерове (табл. 2). Нарастание центральной оси соцветия у новосибирских и алтайских растений наиболее интенсивно до середины цветения. У кемеровских экземпляров статистически значимое отличие этого показателя наблюдается только к третьему измерению: т. е. интенсивность нарастания соцветия в начале вегетации значительно меньше, чем в других регионах.

Суммарное число дихазиев на оси соцветия существенно возрастает с начала до середины цветения. Наибольшее количество дихазиев отмечено на Алтае. Выше указано, что для этих же растений характерна максимальная высота и наименьшая разветвленность надземной части, т. е., вероятно, увеличение линейных размеров компенсирует меньшую горизонтальную мощность растений пустырника.

Доля соцветия в высоте растения - это линейный аналог репродуктивного усилия: расчетного весового показателя (отношение массы генеративных органов к массе побега), являющегося одним из важнейших показателей репродуктивной стратегии растений (Кучер, 2014). Для алтайских растений характерна наиболее высокая доля генеративной части на период начала цветения (около 40 \%). Наименьший вклад соцветия в высоту растения обнаружен у кемеровских растений (37-42 \%), причем в конце цветения разница с другими регионами усиливается. Различия между новосибирскими и алтайскими образцами, достоверные в начале цветения, к концу цветения исчезают (Загурская, Баяндина, 2015b).

В период начала цветения растения из Кемерова и Камлака по ширине генератив- ной части побега (расстоянию между боковыми осями соцветия) статистически значимо не различались, при этом существенно превосходя по этому признаку новосибирские. В конце цветения различия были достоверны во всех регионах. Большее расстояние между боковыми осями соцветия на Алтае отражает наибольший угол отклонения боковых осей соцветия от центральной. В течение сезона наиболее значительно это расстояние изменяется для новосибирских растений, увеличиваясь к концу цветения на $52 \%$, для алтайских - на $36 \%$, а минимальные изменения отмечены для кемеровских (около 23 \%). То есть в Новосибирске наблюдается наиболее интенсивное нарастание боковых осей соцветия в период после начала цветения по сравнению с другими регионами.

Полученные нами результаты согласуются с литературными данными о том, что наиболее интенсивно биопродукционные процессы у пустырника пятилопастного протекают в период первого и второго вегетационных сезонов (Рупасава и др., 1994), при этом сведения о том, что с наступлением цветения функции линейного роста побегов снижаются, подтверждаются только на третьем году жизни растений. Вероятно, растения первого и второго годов жизни затрачивают больше ресурсов на накопление биомассы и адаптацию к условиям окружающей среды, а репродуктивные функции у растений пустырника реализуются в полной мере начиная с третьего года вегетации.

Длина осей соцветия и доля соцветия в высоте растений не только отражают генеративное состояние L. quinquelobatus, но и имеют значение для оценки сырьевого потенциала растений (Государственная фармакопея..., 1990).

L. quinquelobatus цветет с июня до сентября, плоды созревают в августе-октябре, 


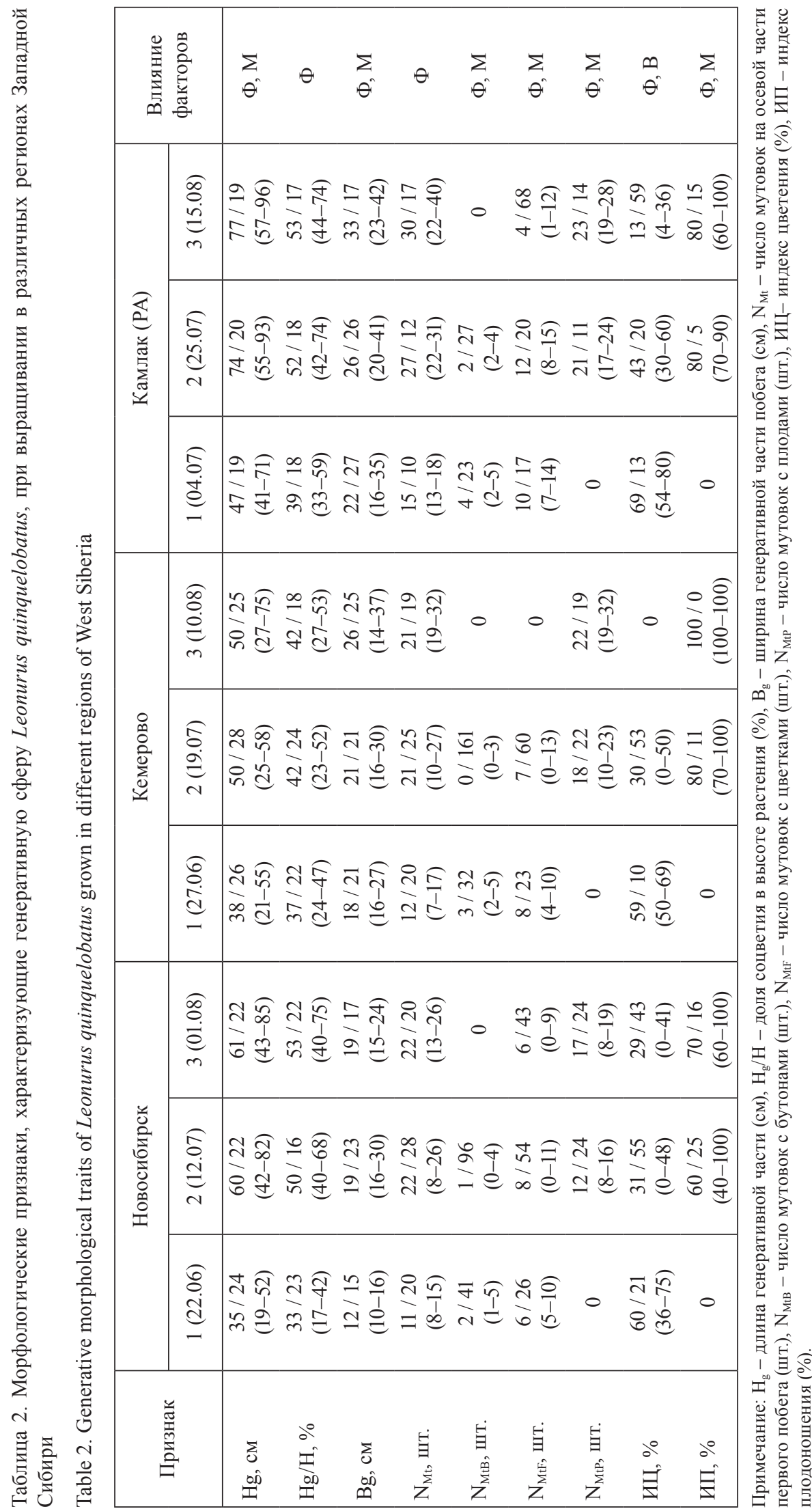


при этом определение перехода из одной фенофазы в другую затруднено. При сборе сырья нами замечено, что переход от одного фенологического состояния растений к другому происходит с задержкой на несколько дней в зависимости от возраста растений и экологических факторов (Загурская и др., 2013). Для более точной дифференциации фенологических состояний растений использовали простые числовые показатели: количество бутонизирующих, цветущих и плодоносящих дихазиев на центральной оси соцветия, характеризующие продолжительность фаз развития и время их смены. Это демонстрируется значениями индекса цветения (ИЦ) и плодоношения (ИП) растений пустырника в регионах исследования (рис. 1). Смена фенофаз происходила в следующем порядке: первыми зацветали и начинали образование плодов растения пустырника в Новосибирске, затем в Кемерове и в последнюю очередь на Алтае; следует отметить также резкое завершение цветения у кемеровских растений (уже в начале августа цветки и бутоны на центральной оси соцветия отсутствовали).

Все эти признаки значительно изменялись в течение сезона, причем для общего количества дихазиев и количества дихазиев с бутонами в период массового цветения выявлены региональные различия между растениями: наибольшее число бутонизирующих элементов соцветия отмечено на Алтае.

Динамика изменения числа дихазиев с цветками и с плодами различалась во всех регионах исследования: для новосибирских растений оказалось характерно относительно стабильное число цветущих элементов на протяжении всех этапов фазы цветения, а в Кемерове к середине августа отмечено полное прекращение цветения центральной оси соцветия.
Основной продуктивный орган растений - листья. Число листьев - один из параметров, характеризующих ассимиляционную способность растений. Листья L. quinquelobatus супротивные, округлые или яйцевидные, пальчато-пятираздельные, сверху ярко-зеленые, снизу светлые; стеблевые - с длинными (7-12 см) черешками (Государственная фармакопея РФ..., 2018).

У растений в Кемерове в среднем насчитывалось 13-18 пар стеблевых листьев, в Новосибирске - 8-12. На Алтае обнаружено не более 7 листовых узлов на вегетативной части побега, причем большинство этих листьев отмирают до цветения, а последние вскоре после его начала, но они характеризовались наибольшими размерами как нижних, так и верхних листьев (табл. 3). В Новосибирске и Кемерове в начале цветения отмечено статистически значимое уменьшение всех параметров листа от нижних к верхним, это особенно заметно на примере кемеровских растений, у которых разница в их расположении составляла около 10 узлов. Незначительное уменьшение длины и ширины листа у новосибирских растений в течение сезона связано с повреждением и отмиранием листьев (в первую очередь их краевых участков), что подтверждается увеличением степени повреждения листьев и изменением узлов расположения.

\section{Заключение}

Показано, что даже при одном происхождении семян и сходных агротехнических мероприятиях региональные условия оказывают существенное влияние на развитие растений L. quinquelobatus: даже в пределах одной географической зоны (юг Западной Сибири) могут реализоваться различные онтогенетические стратегии. Наибольшая разветвленность надземной 
Таблица 3. Параметры листьев Leonurus quinquelobatus при выращивании в различных регионах Западной Сибири

Table 3. Parameters of leaves of Leonurus quinquelobatus grown in different regions of West Siberia

\begin{tabular}{|c|c|c|c|c|c|c|}
\hline \multirow{2}{*}{ Признак } & \multicolumn{2}{|c|}{ Новосибирск } & \multicolumn{2}{|c|}{ Кемерово } & \multicolumn{2}{|c|}{ Камлак (РА) } \\
\hline & $1(22.06)$ & $2(12.07)$ & $1(27.06)$ & $2(19.07)$ & $1(04.07)$ & $2(25.07)$ \\
\hline Число узлов, шт. & $8-12$ & $8-12$ & $13-18$ & - & $6-7$ & - \\
\hline Узел нижнего листа & $4-7$ & $7-9$ & $5-7$ & - & $5-6$ & - \\
\hline \multicolumn{7}{|c|}{ Верхние листья } \\
\hline Длина черешка, см & $2,1 \pm 0,2 *$ & $2,1 \pm 0,2$ & $0,9 \pm 0,1$ & - & $2,6 \pm 0,2$ & - \\
\hline Длина листа, см & $7,1 \pm 0,3$ & $6,6 \pm 0,4$ & $3,7 \pm 0,2$ & - & $8,0 \pm 0,3$ & - \\
\hline Ширина листа, см & $6,0 \pm 0,3$ & $5,6 \pm 0,4$ & $1,5 \pm 0,2$ & - & $7,4 \pm 0,4$ & - \\
\hline Степень повреждения, \% & $27 \pm 5$ & $56 \pm 5$ & $0 \pm 5$ & - & $37 \pm 5$ & - \\
\hline \multicolumn{7}{|c|}{ Нижние листья } \\
\hline Длина черешка, см & $5,5 \pm 0,3$ & $2,7 \pm 0,1$ & $3,3 \pm 0,2$ & - & $3,1 \pm 0,1$ & - \\
\hline Длина листа, см & $6,8 \pm 0,3$ & $6,2 \pm 0,3$ & $7,1 \pm 0,3$ & - & $8,1 \pm 0,3$ & - \\
\hline Ширина листа, см & $8,7 \pm 0,3$ & $6,1 \pm 0,3$ & $8,4 \pm 0,4$ & - & $8,8 \pm 0,4$ & - \\
\hline Степень повреждения, \% & $5 \pm 5$ & $47 \pm 5$ & $70 \pm 5$ & - & $54 \pm 5$ & - \\
\hline
\end{tabular}

Примечание: * среднее арифметическое \pm ошибка среднего.

части отмечена у растений в Новосибирске, что свидетельствует о возможности получения максимальной сырьевой массы. В условиях Горного Алтая (с. Камлак) растения характеризовались наименьшим развитием вегетативной части, при этом реализация репродуктивного потенциала обеспечивалась, в том числе, увеличением размеров соцветия. Кемеровские растения демон- стрировали наиболее быстрое протекание генеративных процессов. Во всех регионах наиболее существенно различались показатели, характеризующие генеративные процессы у растений.

Предложены индексы, позволяющие более четко дифференцировать процессы цветения и плодоношения у растений L. quinquelobatus.

\section{Список литературы / References}

Гаммерман А.Ф., Кадаев Г.Н., Яценко-Хмелевский И.А. (1983) Лекарственные растения. М., Высшая школа, с. 293-295 [Gammerman A.F., Kadaev G. N., Jacenko-Hmelevskij I.A. (1983) Medicinal plants: a textbook for university students. Moscow, Vysshaja shkola, p. 293-295 (in Russian)]

Государственная фармакопея СССР: 11-е изд. (1990) Вып. 2. М., Медицина, с. 327-328 [State Pharmacopoeia of the Union of Soviet Socialist Republics. 11th ed. (1990) Vol. 2. Moscow, Medicina, p. 327-328 (in Russian)]

Государственная фармакопея Российской Федераџии. Изд. 14. (2018) Т. 4. М., Мин-во здрав. РФ, с. 6351-6359 [State Pharmacopoeia of the Russian Federation. 14th ed. (2018) Vol. 4. Moscow, Min. Zdrav. RF, p. 6351-6359 (in Russian)]

Губанов И. А., Киселева К. В., Новиков В. С., Тихомиров В. Н.(2004)Leonurus quinquelobatus Gilib. - Пустырник пятилопастный. Иллюстрированный определитель растений Сред- 
ней России. Т. 3. М., Т-во науч. изд. КМК, с. 129 [Gubanov I. A., Kiseleva K. V., Novikov V.S., Tikhomirov V.N. (2004) Illustrated identification keys for plants in Central Russia. Moscow, KMK Scientific Press Ltd., p. 129 (in Russian)]

Ермохин Ю.И., Шойкин О.Д., Красницкий В.М. (2012) Показатели связи между химическим составом растений и урожаем пустырника пятилопастного. Плодородие, 4: 35-36 [Ermokhin Yu.I., Shoikin O.D., Krasnitsky V.M. (2012) Factors of relationship between the chemical composition of plants and the yield of quinquelobate motherwort (Leonurus quinquelobatus). Fertility [Plodorodie], 4: 35-36 (in Russian)]

Загурская Ю.В., Баяндина И.И. (2015а) Особенности развития генеративной сферы Leonurus quinquelobatus при выращивании в Западной Сибири. Проблемы промышленной ботаники индустриально развитых регионов: материаль IV международной конференции. Кемерово, КРЭОО «Ирбис», с. 38-41 [Zagurskaya Yu.V., Bayandina I. I. (2015a) Some features of generative sphere development in Leonurus quinquelobatus, cultivated in West Siberia. Problems of industrial botany in industrialized regions: conference papers of the V International conference. Kemerovo, KREOO «Irbis», p. 38-41 (in Russian)]

Загурская Ю.В., Баяндина И.И. (2015b) Сезонная и возрастная динамика изменения высоты растений Leonurus quinquelobatus в разных регионах Западной Сибири. Лекарственные растения: фундаментальные и прикладные проблемы: материалы II международной научной конференции. Новосибирск, Изд-во НГАУ, с. 19-21 [Zagurskaya Yu.V., Bayandina I.I. (2015b) Seasonal and age dynamics of plant height in Leonurus quinquelobatus Gilib. in different regions of West Siberia. Medicinal plants: fundamental and applied problems. Proceedings of the II International conference. Novosibirsk, NSAU, p. 19-21 (in Russian)]

Загурская Ю. В., Баяндина И.И., Сиромля Т.И., Сысо А.И., Дымина Е.В., Вронская О. О., Казанцева Л.М. (2013) Качество сырья лекарственных растений при выращивании в антропогенно нарушенных регионах Западной Сибири на примере Hypericum perforatum L. и Leonurus quinquelobatus Gilib. Химия растительного сырья, 4: 141-150 [Zagurskaya Yu.V., Bayandina I.I., Siromlya T.I., Syso A.I., Dymina E.V., Vronskaya O.O., Kazantseva L.M. (2013) Quality of raw medicinal plants (Hypericum perforatum L. and Leonurus quinquelobatus Gilib.) cultivated in the anthropogenic disturbed areas of the Siberian cities. Chemistry of Plant Raw Material [Khimiya rastitel'nogo syr'ya], 4: 141-150 (in Russian)]

Загурская Ю.В., Баяндина И.И., Дымина Е.В., Казанцева Л.М., Шереметов Р.Т. (2012) Влияние температуры воздуха и почвы в четырех регионах Западной Сибири на развитие некоторых лекарственных растений. Продуктивность культурных растений в зависимости от погодных условий. Новосибирск, Новосиб. гос. аграр. ун-т, с. 282-288 [Zagurskaja Yu.V., Bayandina I.I., Dymina E.V., Kazanceva L.M., Sheremetov R.T. (2012) Air and soil temperature effects on the development of some medicinal plants in four regions of West Siberia. Productivity of cultivated plants in relation to weather conditions. Novosibirsk, Novosibirsk State Agrarian University, p. 282-288 (in Russian)]

Загурская Ю.В., Сиромля Т.И. (2018) Оценка элементного химического состава растений Leonurus quinquelobatus (на примере Западной Сибири). Ученые записки Казанского университета. Серия: Естественные науки, 160(3): 419-435 [Zagurskaya Y.V., Siromlya T.I. (2018) Chemical composition of Leonurus quinquelobatus in Western Siberia. Proceedings of Kazan 
University. Natural Sciences Series [Uchenye zapiski Kazanskogo universiteta. Seriya estestvennye nauki], 160(3): 419-435 (in Russian)]

Заугольнова Л.Б., Жукова Л.А., Попадюк Р.В., Смирнова О.В. (1992) Критическое состояние ценопопуляций растений. Проблемы устойчивости биологических систем. М., Наука, с. 51-59 [Zaugol'nova L.B., Zhukova L. A., Popadjuk R. V., Smirnova O. V. (1992) The critical state of plant coenopopulations. Problems of stability of biological system. Moscow, Nauka, p. 51-59 (in Russian)]

Комаревцева Е.К., Курочкина Н.Ю. (2018) Онтоморфогенез Leоnurus glancescens (Lamiaceae) в азиатской части ареала. Растительный мир Азиатской России, 1(29): 24-29 [Komarevtseva E.K., Kurochkina N. Yu. (2018) Ontomorphogenesis of Leonurus glaucescens (Lamiaceae) in the Asian part of it's Range. Plant Life of Asian Russia [Rastitel'nyj mir Aziatskoj Rossii], 1(29): 24-29 (in Russian)]

Кучер Е.Н. (2014) Репродуктивное усилие и репродуктивные тактики видов рода Cephalanthera Rich. в Крыму. Ученые записки Таврического начионального университета им. В. И. Вернадского. Серия «Биология, химия», 27(1): 93-101 [Kucher E. N. (2014) Reproductive effort and reproductive tactics species of the genus Cephalanthera Rich. in Crimea. Scientific Notes of V.I. Vernadsky Taurida Federal University. Biology. Chemistry [Uchenye zapiski Tavricheskogo natsional'nogo universiteta im. V.I. Vernadskogo. Seriya «Biologiya, khimiya»], 27(1): 93-101 (in Russian)]

Макрушин Н. М., Болдырева Л. Л., Савченко М.В. (2017) Влияние способов посева на рост и развитие растений пустырника пятилопастного (Leonurus quinquelobatus L.) в предгорной зоне Крыма. Известия сельскохозяйственной науки Тавриды, 11(174): 20-27 [Makrushin N.M., Boldyreva L.L., Savchenko M.V. (2017) The effect of methods of sowing on the growth and development of the five-blade Motherwort (Leonurus quinquelobatus L.) in the foothill zone of the Crimea. Transactions of Taurida Agricultural Science [Izvestiya sel'skokhozyajstvennoj nauki Tavridy], 11(174): 20-27 (in Russian)]

Романюк Б. П. (2012) Медицинская ботаника: Цитология, гистология, органография с основами физиологии и биохимии. Луганск, ГУ «Луганский государственный медицинский университет», с. 112 [Romanyuk B.P. (2012) Medicinal botany: cytology, histology, organography and basics of physiology and biochemistry. Lugansk, GU «Lugansk State Medical University», p. 112 (in Russian)]

Рупасава Ж. А., Русаленка В. Р., Ігнаценка В. А., Афанаскіна І.П. (1994) Асаблівасці роставых і біяпрадукцыйных працэсау у раслінах сардэчніку пяцілопасцевага і валяр'яну лекавага ва умовах Беларусі. Весиі Наџыянальнай Акадэміі навук Беларусі. Серыя біялагічных навук, 1: 21-27 [Rupasava Zh.A., Rusalenka V.R., Ignacenka V. A., Afanaskina I. P. (1994) Growth and bioproduction processes in five-bladed motherwort and valerian plants in Belarus. Proceedings of the National Academy of Sciences of Belarus, Biological Series [Vestsi Natsyyanal'naj Akademii navuk Belarusi. Seryya biyalagichnykh navuk], 1: 21-27 (in Belorussian)]

Сиромля Т. И., Сысо А. И., Загурская Ю. В., Баяндина И. И. (2017) Эколого-агрохимическая оценка состава и свойств почв ботанических садов юго-востока Западной Сибири. Агрохимия, 10: 16-23 [Siromlya T.I., Syso A.I., Zagurskaya Yu.V., Bayandina I.I. (2017) Ecological and agrochemical evaluation of composition and properties of soils in botanical gardens of the South-East of Western Siberia. Agricultural Chemistry [Agrokhimiya], 10: 16-23 (in Russian)] 
Тарасенко С.А., Брилева С.В., Белоус О.А. (2008) Физиолого-биохимические основы высокой продуктивности лекарственных растений в агроценозах. Гродно, ГГАУ, 191 с. [Tarasenko S. A., Brileva S. V., Belous O. A. (2008) Physiology and biochemistry of high productivity of medicinal plants in agrocenoses. Grodno, GSAU, 191 p. (in Russian)]

Чудновская Г.В. (2013) Leonurus sibiricus L. в Восточном Забайкалье. Фундаментальные исследования, 8-1: 119-122 [Chudnovskaya G. V. (2013) Leonurus sibiricus L. in East Transbaikalia. Fundamental Research [Fundamental'nye issledovaniya], 8-1: 119-122 (in Russian)]

Шевелуха В.С. (1971) Закономерности временного хода ростовых процессов у растений: автореф. дис. ... доктора биол. наук. М., СXА им. К. А. Тимирязева, 50 с. [Sheveluha V.S. (1971) Temporal patterns of growth in plants: abstract. dis. ... doctor of biology. Moscow, SAU K. A. Timiryazeva, 50 p. (in Russian)]

Bozek M. (2000) Daily dynamics of blooming of some species from Lamiaceae family. Annales Universitatis Mariae Curie-Sklodowska, 8: 117-127

Ganeva Ts., Tsenov B., Stefanova M., Koleva D. (2015) Assessment of regenerative potential of in vitro and ex vitro Leonurus cardiaca L. plants by anatomical markers. Oxidation Communications, 38(3): 1305-1313

Pitschmann A., Waschulin C., Sykora C., Purevsuren S., Glasl S. (2017) Microscopic and phytochemical comparison of the three Leonurus species L. cardiaca, L. japonicus, and L. sibiricus. Planta Medica, 83(14-15): 1233-1241

Marciniuk P., Gawronska B., Marciniuk J., Joachimiak A. J. (2014) Taxonomic individuality of Leonurus cardiaca and Leonurus quinquelobatus in view of morphological and molecular studies. Plant Systematics and Evolution, 300(2): 255-261

Ritter M., Melichar K., Strahler S., Kuchta K., Schulte J., Sartiani L., Cerbai E., Mugelli A., Mohr F.-W., Rauwald H.W., Dhein S. (2010) Cardiac and electrophysiological effects of primary and refined extracts from Leonurus cardiaca L. (Ph. Eur.). Planta Medica, 76(6): 572-582

Rastogi S., Pandey M.M., Rawat A.K.S. (2016) Traditional herbs: A remedy for cardiovascular disorders. Phytomedicine, 23(11): 1082-1089 